\title{
Abnormal expression levels of BMP15/Smad1 are associated with granulosa cell apoptosis in patients with polycystic ovary syndrome
}

\author{
XIANGRONG CUI ${ }^{1,2^{*}}$, XUAN JING $^{3 *}$, XUEQING WU $^{1}$, XINGYU BI $^{1}$, JUNFEN LIU $^{1}$, ZHIJING LONG ${ }^{1}$, \\ XIUPING ZHANG ${ }^{1}$, DONGDONG ZHANG ${ }^{1}$, HONGXIANG JIA ${ }^{1}$, DAN SU ${ }^{1}$ and KAI HUO ${ }^{4}$ \\ ${ }^{1}$ Reproductive Medicine Center, Children's Hospital of Shanxi and Women Health Center of Shanxi; ${ }^{2}$ Clinical \\ Laboratory, The Central Hospital of Linfen; ${ }^{3}$ Clinical Laboratory, Shanxi Province People's Hospital; \\ ${ }^{4}$ Department of Neurosurgery, The Tumor Hospital of Shanxi, Taiyuan, Shanxi 030000, P.R. China
}

Received June 15, 2016; Accepted April 13, 2017

DOI: $10.3892 / \mathrm{mmr} .2017 .7658$

\begin{abstract}
Polycystic ovary syndrome (PCOS) is a common endocrine disorder that affects reproductive dysfunction and metabolism in women of childbearing age. An increasing number of studies have suggested that the bone morphogenetic protein 15 (BMP15) signalling pathway serves an important role in the pathogenesis of PCOS; however, the full mechanism remains unknown. The present study revealed that intrinsic follicular dysplasia may be associated with regulation disorders of ovarian granulosa cell apoptosis. Compared with the control group, body mass index, luteinising hormone and testosterone levels were significantly increased $(\mathrm{P}<0.05)$. The percentage of $\mathrm{S}$ phase cells was significantly higher, cells in G2/M phase cells was significantly lower, and cells undergoing apoptosis was significantly higher in the PCOS group compared with the control group $(\mathrm{P}<0.05)$. The expression levels of B-cell lymphoma 2 was significantly decreased in granulosa cells of PCOS group, whereas the expression of caspase- 3 was higher than the control group $(\mathrm{P}<0.05)$. The rate of apoptosis of granulosa cells was measured by a terminal deoxynucleotide transferase dUTP nick-end labelling assay. The relative mRNA expression levels of BMP receptor 2 and SMADI were significantly decreased in granulosa cells in the PCOS group compared with the control $(\mathrm{P}<0.05)$. In addition, the expression of BMP15 in follicular fluid and Smad1
\end{abstract}

Correspondence to: Professor Xueqing $\mathrm{Wu}$, Reproductive Medicine Center, Children's Hospital of Shanxi and Women Health Center of Shanxi, 13 Xinmin North Street, Xinghua Ling, Taiyuan, Shanxi 030000, P.R. China

E-mail: xueqingwu416@163.com

*Contributed equally

Key words: bone morphogenetic protein 15, mothers against decapentaplegic homolog 1, apoptosis, granulosa cells, polycystic ovary syndrome in granulosa cells was significantly decreased in the PCOS group compared with the control $(\mathrm{P}<0.05)$. The data suggested that the BMP15/Smad1 signalling pathway may be involved in granulosa cell apoptosis, and may be a target for clinical treatment for PCOS.

\section{Introduction}

Polycystic ovary syndrome (PCOS) is a common disorder that affects reproductive function in women, affecting 5-10\% of women of reproductive age $(1,2)$. It is the primary reason for ovulation inhibition, infertility and irregular menstruation in women. As its underlying aetiology and pathophysiology remains to be fully understood, endocrine, immunological and genetic factors require further investigation to aid the identification of more effective treatments $(3,4)$. Recently, a study demonstrated that cross-talk between granulosa cells (GCs) and oocytes in the follicle is a key process in oocyte maturation and metabolism (5). Disorders of follicular development in PCOS were closely associated with apoptosis of GCs (6-8).

Bone morphogenetic proteins (BMPs) are functionally involved in all stages of folliculogenesis, and are multifunctional growth factors that belong to the transforming growth factor $\beta$ (TGF $\beta)$ superfamily. Their actions are mediated by BMP receptors (BMPRs), which share differing degrees of affinity for their ligands (9-11). The oocyte-secreted factor, BMP15, is a ligand of the TGF $\beta$ superfamily that mediates Smad1 signalling pathway when it binds to BMPR2. Following the activation of receptor kinases by ligand binding, downstream signalling molecules are activated, and subsequently modulate the expression of target genes. Previous studies have demonstrated that BMP15 serves a role in follicular growth and oocyte quality, and was downregulated in PCOS patients (12). It has additionally been revealed that the state of the oocyte may reversely influence granulosa cell proliferation, and following removal of oocytes, apoptosis of granulosa cells increased. However, when BMP15 was added to the cultures, it significantly reduced apoptosis of granulosa cells $(10,12)$. Therefore, it is of value to investigate the effect of BMP15 on apoptosis of granulosa cells, and whether this effect 
is associated with BMPs and the Smad signalling pathway in PCOS.

In the present study, the expression of B-cell lymphoma 2 (Bcl-2), caspase-3, Smad1, BMP15 and BMPR2 was investigated in granulosa luteinizing cells from women affected by PCOS, compared with healthy ovulatory women. The present study aimed to investigate the involvement of the BMP15/Smad1 signalling pathway in granulosa cell of PCOS women, and the underlying mechanism.

\section{Materials and methods}

Patients. The study population consisted of women who were referred to the Reproductive Medicine Centre of Shanxi Women and Infants Hospital (Taiyuan, China), between May 2014 and May 2015. All patients were of Han ethnicity, from Shanxi, North China. Informed written consent was obtained from each patient and the study was approved by the Reproductive Ethics Committee of the Children's Hospital of Shanxi and Women's Health Center of Shanxi (Taiyuan, China).

Individual follicular fluid and serum samples were collected from 138 women undergoing in vitro fertilization (IVF)/intracytoplasmic sperm injection (ICSI) treatment. Patients with PCOS $(n=70)$ were selected based on the 2003 Rotterdam criteria (13). The diagnosis of PCOS was based on the association of two out of three of the following criteria: i) Oligomenorrhea and/or anovulation; ii) clinical and/or biological hyperandrogenism; iii) polycystic ovaries. Patients with endometriosis, congenital adrenal hyperplasia, hypothyroidism, androgen-secreting tumours, Cushing's syndrome and other diseases that interfere with the hypothalamuspituitary-ovary axis were excluded from the study. The control group $(n=68)$ were women undergoing fertility treatment due to male infertility or tubal infertility disorders, although they experienced regular menstrual cycles.

All patients did not present with cardiovascular system diseases, thyroid abnormalities or other endocrine metabolic disorders.

Controlled ovarian hyperstimulation protocol. The present study obtained standard operating procedures from embryologists and physicians. Patients with PCOS received a monophasic combined oral contraceptive pill for 28 consecutive days.

Patients with PCOS were pretreated with protection of the endometrium, adjustment of the menstrual cycle, and downregulation of hyperandrogenism prior to the downregulation protocol using oral ethinylestradiol [Diane ${ }^{\circledR}-35$ (Bayer HealthCare Pharmaceuticals; Bayer AG, Leverkusen, Germany) or Marvelon ${ }^{\circledR}$ (Organon Pharmaceuticals; Merck KGaA, Darmstadt, Germany)]. All women underwent controlled ovarian hyper-stimulation with the gonadotropin releasing hormone agonist long protocol (14), and pituitary suppression was commenced with leuprolide acetate (Diphereline ${ }^{\circledR}$; GeneScience Pharmaceuticals Co., Ltd., Changchun, China) at a dose of $0.05 \mathrm{mg} / \mathrm{day}$, during the mid-luteal phase of the preceding cycle. Complete pituitary suppression was confirmed by serum follicle-stimulating hormone (FSH) levels of $<5 \mathrm{mIU} / \mathrm{ml}$, luteinising hormone $(\mathrm{LH}) \leq 5 \mathrm{mIU} / \mathrm{ml}$, estradiol $\left(\mathrm{E}_{2}\right)<50 \mathrm{pg} / \mathrm{ml}$, bilateral antral follicle diameter $<5 \mathrm{~mm}$ and endometrial thickness $\leq 5 \mathrm{~mm}$.
Urofollitropin (Lizhu Pharmaceutical Trading Co., Ltd., Nanjing, China) was used at doses ranging between 75 and $300 \mathrm{IU} /$ day in accordance with patient age, body mass index (BMI), size and number of antral follicles and serum FSH levels. The dosage of urofollitropin was adjusted according to ovarian response, which was assessed by ultrasound and serum $E_{2}$ levels. Treatment with urofollitropin was continued until $\geq 2$ follicles had reached $18 \mathrm{~mm}$ in diameter. Treatment with $250 \mu \mathrm{g}$ subcutaneous human chorionic gonadotropin (HCG; Lizhu Pharmaceutical Trading Co., Ltd.) was subsequently administered to stimulate follicle maturation. Oocyte retrieval was performed with the guidance of ultrasound 34-36 $\mathrm{h}$ after HCG injection. Routine IVF or ICSI procedures were performed, and two embryos were transferred 3-5 days after oocyte retrieval using ultrasound guidance. Pregnancy was diagnosed by a rising concentration of serum or urine $\beta$-HCG, which was measured 14 days after embryo transfer. The fertilization rate was defined as the percentage of fertilized embryos (2 pronuclei) in the mature oocytes. Clinical pregnancy was defined as the presence of a gestational sac or heartbeat during vaginal ultrasound examination 4 weeks after embryos transfer. Miscarriage was defined as pregnancy loss before 28 weeks.

Clinical measurements. Medical information was collected and recorded, including age, BMI, menarche age, serum basic sexual hormone levels, retrieved oocyte number, mature oocyte rate, fertilization rate, portable embryo rate, high-quality embryo rate and clinical pregnancy rate.

Collection of follicular fluid and granular cells. After oocyte retrieval, the follicular fluids from each patient were pooled and stored in a tube at $37^{\circ} \mathrm{C}$. Cells and supernatant were separated by centrifugation for $30 \mathrm{~min}$ at 2,200 x g at room temperature. Supernatants were collected in a tube for analysis of BMP15. The cell pellet was resuspended in $1 \mathrm{ml}$ PBS. The suspension was overlayed on $1 \mathrm{ml}$ Ficoll (Tianjin Haoyang Biological Products Technology Co., Ltd., Tianjin, China) and was centrifuged at $1,000 \mathrm{x} \mathrm{g}$ at room temperature for $15 \mathrm{~min}$. Granular cells were aspirated from the interface, washed with PBS three times and counted on a Neubauer haemocytometer. Cells were either used for the terminal deoxynucleotide transferase dUTP nick-end labelling (TUNEL) assay or stored at $-80^{\circ} \mathrm{C}$ for mRNA, protein and cell cycle analysis.

Serum collection and analysis. Blood samples were taken between 8:00 and 9:00 am after a 12 h overnight fast, and collected into a tube containing EDTA. The samples were centrifuged at 2,200 $\mathrm{xg}$ at room temperature for $3 \mathrm{~min}$ and the serum and buffy coat were separated. Serum was either used for testing sex hormone levels or was stored at $-80^{\circ} \mathrm{C}$.

Reverse transcription-quantitative polymerase chain reaction (RT-qPCR). RT-qPCR was used to assess the mRNA expression levels of BMPR2, BCL2, CASP3 and SMAD1. Total RNA was extracted from granular cells using the RNAsimple Total RNA kit (Tiangen Biotech Co., Ltd., Beijing, China), and was reverse-transcribed using a kit from Takara Bio, Inc. (Otsu, Japan). A SYBR Green kit (Takara Bio, Inc.) was used as described previously (15). The ACTB gene that encodes the 
$\beta$-actin protein was used as the endogenous housekeeping gene for normalization. The PCR was performed at $93^{\circ} \mathrm{C}$ for $2 \mathrm{~min}$, followed by a total of 40 cycles at $93^{\circ} \mathrm{C}$ for $1 \mathrm{~min}$ and $55^{\circ} \mathrm{C}$ for $2 \mathrm{~min}$. Primers sequences were as follows: Forward, 5'-AAT ACTCGCACTTCCTCAGAACC-3' and reverse 5'-AGCATA GCAAGGCTTCAGACAG-3' for BMPR2; forward, 5'-GTC ATCGTTGGGCAGAAGTTT-3' and reverse, 5'-GAAGAC TCAACATGGGCTCTAAA-3' for $S M A D 1$; forward, 5'-GGT GGGGTCATGTGTGTGG-3' and reverse, 5'-CGGTTCAGG TACTCAGTCATCC-3' for BCL2; forward, 5'-CATGGA AGCGAATCAATGGACT-3' and reverse, 5'-CTGTACCAG ACCGAGATGTCA-3' for CASP3; forward, 5'-TGTACG TTGCTATCCAGGCT-3' and reverse, 5'-CTCCTTAATGTC ACGCACGA-3' for $A C T B$. The $2^{-\triangle \Delta C q}$ method was used for quantification (16).

Western blotting analysis. Follicular fluids were prepared from all patients for western blotting analysis to determine the expression levels of BMP15 (17). Cell lysates were prepared in lysis buffer (Nanjing KeyGen Bio Tech Co., Ltd., Nanjing, China) for the measurement of Smad1, Bcl-2 and caspase-3 expression. Protein concentration was determined using a bicinchoninic acid assay kit. A total of $50 \mu \mathrm{g}$ protein/lane was separated by SDS-PAGE on a $10 \%$ gel and blotted onto polyvinylidene difluoride membranes (Merck KGaA). The membranes were blocked with $5 \%$ bovine serum albumin (Beyotime Institute of Biotechnology, Haimen, China) for $1 \mathrm{~h}$ at room temperature and incubated with rabbit anti-BMP15 (catalog no. 18982-1-AP; 1:500; ProteinTech Group, Inc., Chicago, IL, USA) Smad-1 (catalog no. 10429-1-AP; 1:500; ProteinTech Group, Inc.), caspase-3 (catalog no. 19677-1-AP; 1:500; ProteinTech Group, Inc.), Bcl-2 (catalog no. 12789-1-AP; 1:1,000; ProteinTech Group, Inc.) and $\beta$-actin (catalog no. 60008-1-Ig, 1:2,000; ProteinTech Group, Inc.) in TBS with Tween-20 (TBST) with 5\% non-fat milk at $4^{\circ} \mathrm{C}$ overnight. Membranes were subsequently probed with a horseradish peroxidase-conjugated goat anti-rabbit secondary antibody (1:2,000; Protein Tech Group Inc.; catalog no. SA00001-2) at room temperature for $1 \mathrm{~h}$. The proteins of interest were detected using enhanced chemiluminescence (Beyotime Institute of Biotechnology) and analysed using Image-Pro Plus software (version 5.1; Media Cybernetics, Inc., Rockville, MD, USA).

Cell cycle analysis. The cell cycle distribution was analysed using a flow cytometer (FACSAria II; BD Biosciences, Franklin Lakes, NJ, USA). Granular cells were pooled and stored in tubes at a density of $1.6 \times 10^{5}$ cells per tube. Cells were fixed in $70 \%$ ethanol for $24 \mathrm{~h}$ at $4^{\circ} \mathrm{C}$ and washed three times with PBS. Finally, the cell pellets were stained with RNase (1 mg/ml, Thermo Fisher Scientific, Inc. Waltham, MA, USA) and $400 \mu \mathrm{l}$ propidium iodide solution $(100 \mu \mathrm{l} / \mathrm{ml})$ for $30 \mathrm{~min}$ in the dark and analysed by flow cytometry using ModFit LT software (version 3.2; Verity Software House, Inc., Topsham, ME, USA). Each experiment was repeated at least three times.

TUNEL assay. Granular cells ( $1 \times 10^{5}$ cells/well) were fixed in $4 \%$ paraformaldehyde solution for $20 \mathrm{~min}$ and permeabilized in $0.1 \%$ Triton $\mathrm{X}-100$ in $0.1 \%$ citrate solution for $5 \mathrm{~min}$ at room temperature in 24-well plates. Subsequently, granular cells
Table I. Comparison of clinicopathological factors in PCOS and control patients.

\begin{tabular}{lccc}
\hline Parameters & PCOS group & Control group & P-value \\
\hline Age & $29.01 \pm 3.56$ & $28.47 \pm 3.52$ & 0.37 \\
BMI & $25.37 \pm 6.73$ & $22.62 \pm 5.81$ & $0.01^{\mathrm{a}}$ \\
Menarche age & $13.11 \pm 1.25$ & $13.58 \pm 1.47$ & 0.81 \\
FSH $(\mathrm{mIU} / \mathrm{ml})$ & $6.70 \pm 1.35$ & $6.88 \pm 1.67$ & 0.49 \\
LH $(\mathrm{mIU} / \mathrm{ml})$ & $10.95 \pm 7.12$ & $4.73 \pm 1.54$ & $<0.0001^{\mathrm{a}}$ \\
$\mathrm{E}_{2}(\mathrm{pg} / \mathrm{ml})$ & $57.32 \pm 14.74$ & $55.28 \pm 18.31$ & 0.47 \\
PRL $(\mathrm{ng} / \mathrm{ml})$ & $13.77 \pm 5.89$ & $14.23 \pm 5.62$ & 0.64 \\
TES $(\mathrm{ng} / \mathrm{dl})$ & $92.80 \pm 15.53$ & $45.91 \pm 18.20$ & $<0.0001^{\mathrm{a}}$ \\
\end{tabular}

${ }^{\mathrm{a}} \mathrm{P}<0.05$ vs. control group. PCOS, polycystic ovary syndrome; BMI, body mass index; FSH, follicle stimulating hormone; LH, luteinizing hormone; $\mathrm{E}_{2}$, estradiol; PRL, progesterone; TES testosterone; PRL, prolactin.

were incubated in TUNEL reaction medium (Nanjing KeyGen Biotech Co., Ltd.) for $1 \mathrm{~h}$ at $37^{\circ} \mathrm{C}$ in the dark. After the reaction was stopped, granular cells were washed three times in PBS and the cell nuclei were labelled with streptavidin-horseradish peroxidase (Nanjing KeyGen Bio Tech Co., Ltd.) for 30 min at room temperature in the dark. A total of 1-5 drops diaminobenzidine chromogen solution was added to the cells and incubated for $5 \mathrm{~min}$ at room temperature. Cells were visualized under a brightfield microscope at x200 magnification. TUNEL-positive cells appeared to be brown or buffy. The total number of cells and the number of apoptotic cells were counted in a randomly-selected visual field in each group. Negative control cells were subjected to the TUNEL assay without the addition of terminal deoxynucleotidyl transferase in the reaction mixture. Positive control cells were incubated with $100 \mu 1$ DNase I solution prior to the TUNEL assay, in order to induce DNA strand degradation.

Statistical analysis. Statistical analysis was performed using the SPSS software version 17.0 (SPSS, Inc., Chicago, IL, USA). Normally distributed data were expressed as the mean \pm standard deviation. To check the normality of the distribution, the Shapiro-Wilk test was performed. Two-tailed Student's t-test was used to assess differences in values between each group. $\mathrm{P}<0.05$ was considered to indicate a statistically significant difference.

\section{Results}

Comparison of conditions and IVF outcomes between PCOS and control patients. Tables I and II summarize the medical information and IVF outcomes of patients. Compared with the control group, the BMI and the levels of LH and testosterone (TES) were significantly increased, whereas the portable embryo rate was significantly decreased $(\mathrm{P}<0.05)$.

Comparison of apoptosis status in granulosa cells between the PCOS and control groups. As demonstrated in Fig. 1A and $\mathrm{B}$, there was no significant difference in the percentage of cells 
Table II. Comparison of in vitro fertilization outcomes in PCOS and control patients.

\begin{tabular}{lccr}
\hline Parameters & PCOS group & Control group & P-value \\
\hline Retrieved oocyte number (n) & $23.61 \pm 2.77$ & $17.35 \pm 1.93$ & 1.65 \\
Mature oocytes rate (\%) & $78.71(1301 / 1653)$ & $78.98(932 / 1180)$ & 0.86 \\
Fertilization rate (\%) & $66.24(1095 / 1653)$ & $67.29(794 / 1180)$ & 0.56 \\
Portable embryo rate (\%) & $86.39(946 / 1095)$ & $90.05(715 / 794)$ & $0.02^{\mathrm{a}}$ \\
High-quality embryo rate (\%) & $56.98(539 / 956)$ & $60.62(440 / 715)$ & 0.06 \\
Clinical pregnancy rate $(\%)$ & $47.14(33 / 70)$ & $52.94(36 / 68)$ & 0.50 \\
\hline
\end{tabular}

${ }^{a} \mathrm{P}<0.05$ versus control group. $\mathrm{PCOS}$, polycystic ovary syndrome.

in $\mathrm{G} 0 / \mathrm{G} 1$ between the PCOS and control groups $(\mathrm{P}>0.05)$. In the PCOS group, the percentage of cells in $\mathrm{S}$ phase was significantly higher, the percentage of cells in G2/M phase was significantly lower and the apoptosis peak was significantly higher, compared with the control group $(\mathrm{P}<0.05)$. RT-qPCR (Fig. 1C) and western blotting (Fig. 1D) demonstrated that the expression levels of the gene encoding Bcl-2 and its corresponding protein were significantly decreased in granulosa cells of PCOS group compared to control group $(\mathrm{P}<0.05)$, whereas the expression of gene encoding caspase- 3 and its corresponding protein was higher than control group $(\mathrm{P}<0.05)$. As demonstrated in Fig. 1E, the level of apoptosis in granulosa cells was measured by a TUNEL assay. The level of apoptosis in granulosa cells was $21.47 \pm 6.81$ in the PCOS group, which was significantly greater than the control group $(\mathrm{P}<0.05$; $14.78 \pm 4.58$ ) (data not shown). Cells in 20 randomly-selected fields (magnification, x200) were counted by eye.

Comparison of BMP15 in follicular fluid and BMPR2 and Smadl in granulosa cells of the PCOS and control groups. As demonstrated in Fig. 2A, the relative mRNA expression levels of $B M P R 2$ and $S M A D 1$ were significantly decreased in granulosa cells of the PCOS group compared with the control group $(\mathrm{P}<0.05)$. Western blot analysis (Fig. 2B) demonstrated that the expression of BMP15 in follicular fluid and Smad1 in granulosa cells was reduced in the PCOS group compared with the control group.

\section{Discussion}

PCOS is the most prevalent female endocrinopathy and is the largest single cause of anovulatory infertility. It is classically characterized by chronic anovulation, hyperandrogenism and a polycystic ovarian morphology, as revealed by ultrasonography $(16,18,19)$. PCOS has been defined as a metabolic syndrome associated with obesity, insulin resistance, type 2 diabetes, dyslipidaemia, hypertension and other cardiovascular diseases (20-22). The present study demonstrated that BMI, LH and TES were significantly increased, whereas portable embryo rate was significantly decreased in PCOS patients compared with healthy controls. However, the pathogenesis of PCOS remains unclear.

Recently, researchers have hypothesised that the pathogenesis of PCOS may be due to a combination of genetic and environmental factors, where the follicle microenvironment affects the quality of oocytes and cleavage quality (23-25). Granulosa cells are key somatic cells in the follicle microenvironment, and serve an important role in oocyte maturation and follicular development. Follicular development is accompanied by growth, proliferation, differentiation and maturation of granulosa cells. Studies have demonstrated that intrinsic follicular dysplasia may be associated with regulation disorders of ovarian granulosa cell apoptosis $(6,26,27)$. Research on ovarian granulosa cell apoptosis in patients with PCOS may provide an insight into the pathological mechanisms and generate novel clinical treatments. Therefore, the present study investigated apoptosis of granulosa cells. There was no significant difference in the percentage of cells in the G0/G1 phase between the PCOS and control groups. The percentage of cells in $\mathrm{S}$ phase was significantly higher, cells in $\mathrm{G} 2 / \mathrm{M}$ phase was significantly lower and the degree of apoptosis was significantly higher in the PCOS group compared with the control group. Bcl-2 is an anti-apoptotic protein and caspase- 3 serves a central role in the apoptotic execution pathway. Therefore, the present study measured the expression levels of these proteins. Expression of Bcl-2 was significantly decreased in granulosa cells of the PCOS, whereas expression of caspase-3 was higher compared to the control group. This suggested that there was a greater degree of apoptosis in the PCOS group.

BMPs belong to the TGF $\beta$ superfamily and have been implicated in the control and regulation of follicular development and female fertility. As an oocyte-secreted factor, BMP15 serves a crucial role in follicular growth and oocyte quality, which is underexpressed in PCOS patients. Adding BMP15 to cultures significantly reduced the apoptosis of granulosa cells $(9,28-30)$. Therefore, it is of value to investigate the effect of BMP15 on the apoptosis of granulosa cells in PCOS $(11,12,31)$. In the present study, the expression of BMP15 in follicular fluid, and BMPR2 and Smad1 expression levels were measured in granulosa cells of women with PCOS undergoing ovarian stimulation for IVF. The mRNA expression levels of $B M P R 2$ and SMAD1 were significantly decreased in granulosa cells of the PCOS group compared to the control group and the expression of BMP15 in follicular fluid was significantly decreased in PCOS group. Therefore, this suggested that the BMP15/Smad1 signalling pathway may be associated with apoptosis of granulosa cells in PCOS.

In the present study, oocyte-secreted factor BMP15 was detected in follicular fluid of mature follicles, and the expression of BMP15 was significantly decreased in the PCOS 

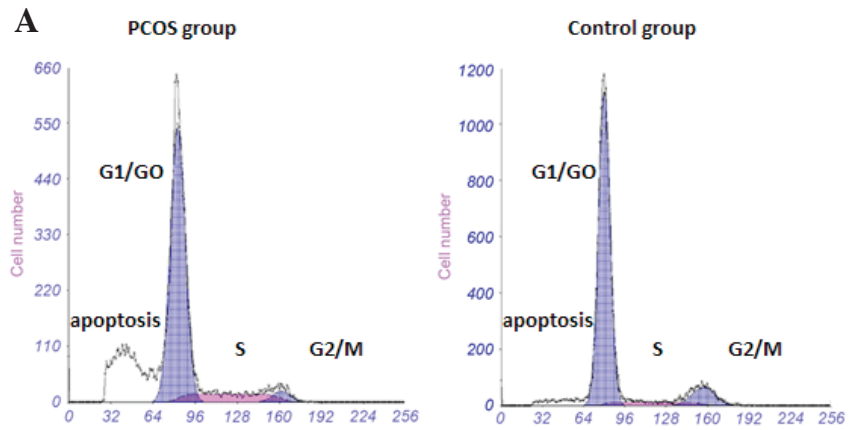

B

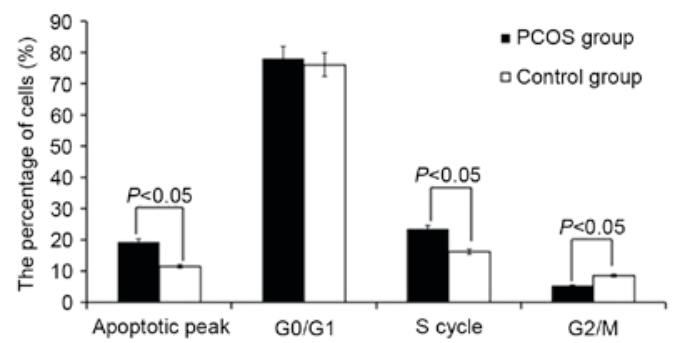

C

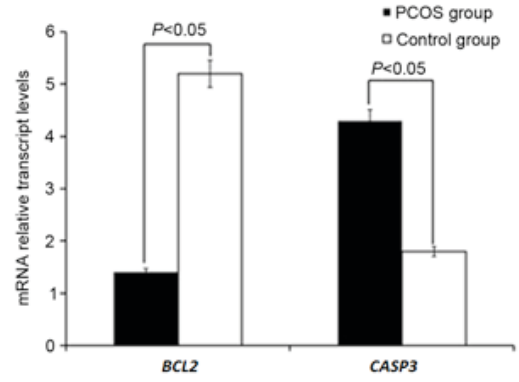

D

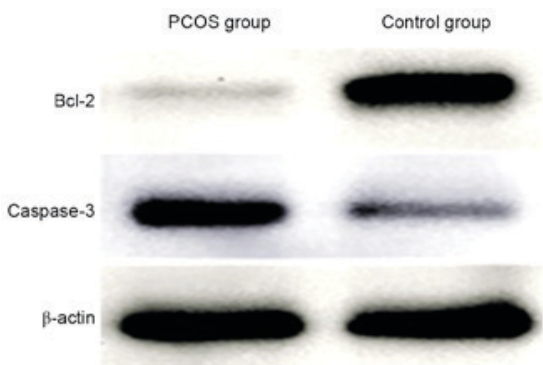

$\mathbf{E}$

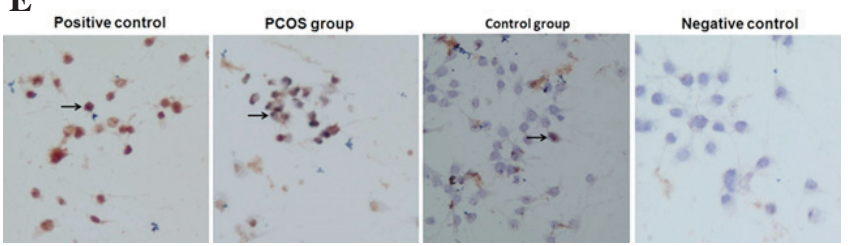

Figure 1. Comparison of apoptosis status in granulosa cells between the PCOS group and the control group. (A) The cell cycle distribution of the cells was analysed using a flow cytometer. (B) The percentage of S phase cells was significantly higher in the PCOS group than the control group, whereas the percentage of cells in G2/M phase was significantly lower in the PCOS group. The apoptotic peak was significantly higher in the PCOS group than the control group $(\mathrm{P}<0.05)$. (C) RT-qPCR analysis demonstrated that the mRNA expression level of $B C L 2$ was significantly decreased in granulosa cells of the PCOS group compared with the control group $(\mathrm{P}<0.05)$, whereas the expression level of $C A S P 3$ was higher than the control group $(\mathrm{P}<0.05)$. (D) Western blot analysis revealed that the protein expression level of Bcl-2 was significantly decreased in granulosa cells of the PCOS group compared with the control group, whereas the expression of caspase- 3 was higher than the control group. (E) TUNEL assay showing the apoptosis in granulosa cells. The buffy nucleus indicate TUNEL-positive cells (black arrows). Slides were observed under a microscope (magnification, x200). Data are expressed as the mean \pm standard deviation. PCOS, polycystic ovary syndrome; $B C L 2$, B-cell lymphoma 2; CASP3, caspase 3; TUNEL, terminal deoxynucleotide transferase dUTP nick-end labelling.
A

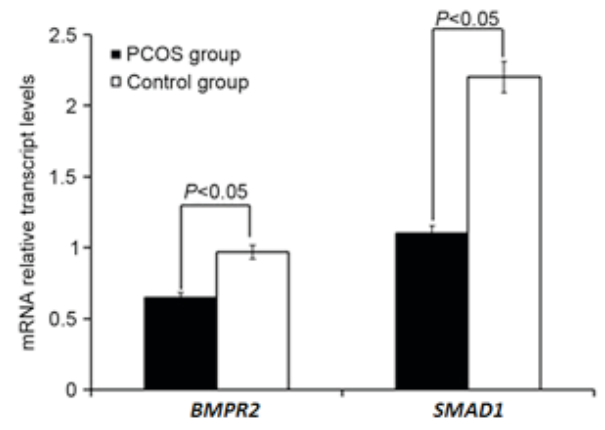

B

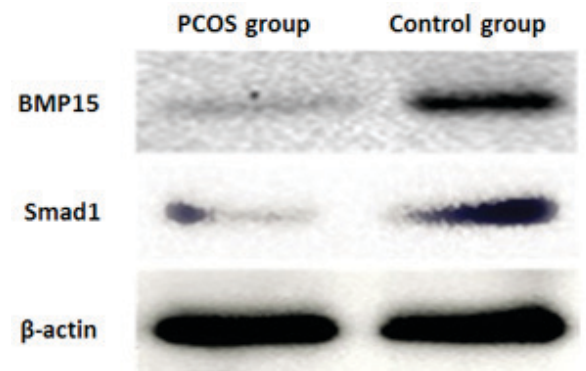

Figure 2. Comparison of BMP15 in follicular fluid and BMPR2 and Smad1 in granulosa cells of the PCOS and control groups. (A) The relative mRNA expression levels of $B M P R 2$ and SMAD1 were significantly decreased in granulosa cells of the PCOS group compared with the control group $(\mathrm{P}<0.05)$. Data are expressed as the mean \pm standard deviation. (B) Western blot analysis revealed that the expression levels of BMP15 in follicular fluid and Smad1 in granulosa cells was reduced in the PCOS group compared with the control group. PCOS, polycystic ovary syndrome; BMPR2, bone morphogenetic protein receptor 2; BMP15, bone morphogenetic protein 15 .

group. Aberrations in the BMP15 signalling pathway may affect oocyte maturation disorders and reduce the developmental potential. In addition, there was increased apoptosis of granulosa cells and alterations in the expression levels of apoptotic proteins in PCOS, suggesting that this may be associated with abnormal alterations in the BMP15 signalling pathway; however, this requires further investigation.

\section{References}

1. Ganie MA, Marwaha RK, Dhingra A, Nisar S, Mani K, Masoodi S, Chakraborty S and Rashid A: Observation of phenotypic variation among Indian women with polycystic ovary syndrome (PCOS) from Delhi and Srinagar. Gynecol Endocrinol 32: 566-570, 2016.

2. Kondo M, Osuka S, Iwase A, Nakahara T, Saito A, Bayasula, Nakamura T, Goto M, Kotani T and Kikkawa F: Increase of kisspeptin-positive cells in the hypothalamus of a rat model of polycystic ovary syndrome. Metab Brain Dis 31: 673-681, 2016.

3. Rissanen AP, Koskela-Koivisto T, Hägglund H, Koponen AS, Aho JM, Pöyhönen-Alho M, Tiitinen A, Tikkanen HO and Peltonen JE: Altered cardiorespiratory response to exercise in overweight and obese women with polycystic ovary syndrome. Physiol Rep 4: pii: e12719, 2016.

4. Casarini L, Simoni M and Brigante G: Is polycystic ovary syndrome a sexual conflict? A review. Reprod Biomed Online 32: 350-361, 2016.

5. Lei X, Cui K, Li Z, Su J, Jiang J, Zhang H, Liu Q and Shi D: BMP-1 participates in the selection and dominance of buffalo follicles by regulating the proliferation and apoptosis of granulosa cells. Theriogenology 85: 999-1012, 2016.

6. Zhang Q, Liu D, Zhang M, Li N, Lu S, Du Y and Chen ZJ: Effects of brain-derived neurotrophic factor on oocyte maturation and embryonic development in a rat model of polycystic ovary syndrome. Reprod Fertil Dev: Jun 25, 2015 (Epub ahead of print). 
7. Kim E, Seok HH, Lee SY, Lee DR, Moon J, Yoon TK, Lee WS and Lee KA: Correlation between expression of glucose transporters in granulosa cells and oocyte quality in women with polycystic ovary syndrome. Endocrinol Metab (Seoul) 29: 40-47, 2014.

8. Huang X, Hao C, Shen X, Zhang Y and Liu X: RUNX2, GPX3 and PTX3 gene expression profiling in cumulus cells are reflective oocyte/embryo competence and potentially reliable predictors of embryo developmental competence in PCOS patients. Reprod Biol Endocrinol 11: 109, 2013.

9. Wei LN, Huang R, Li LL, Fang C, Li Y and Liang XY: Reduced and delayed expression of GDF9 and BMP15 in ovarian tissues from women with polycystic ovary syndrome. J Assist Reprod Genet 31: 1483-1490, 2014.

10. van Houten EL, Laven JS, Louwers YV, McLuskey A, Themmen AP and Visser JA: Bone morphogenetic proteins and the polycystic ovary syndrome. J Ovarian Res 6: 32, 2013.

11. Khalaf M, Morera J, Bourret A, Reznik Y, Denoual C, Herlicoviez M, Mittre H and Benhaim A: BMP system expression in GCs from polycystic ovary syndrome women and the in vitro effects of BMP4, BMP6, and BMP7 on GC steroidogenesis. Eur J Endocrinol 168: 437-444, 2013.

12. Zhao SY, Qiao J, Chen YJ, Liu P, Li J and Yan J: Expression of growth differentiation factor- 9 and bone morphogenetic protein-15 in oocytes and cumulus granulosa cells of patients with polycystic ovary syndrome. Fertil Steril 94: 261-267, 2010.

13. Rotterdam ESHRE/ASRM-Sponsored PCOS consensus workshop group: Revised 2003 consensus on diagnostic criteria and long-term health risks related to polycystic ovary syndrome. Hum Reprod 19: 41-47, 2004.

14. Sarhan A, Harira M, Elshazly S and Nouh A: Comparing stimulation requirements and final outcome between early follicular and mid luteal pituitary suppression in the long gonadotropin releasing hormone agonist protocol. JBRA Assist Reprod 20: 59-61, 2016.

15. Cui X, Jing X, Wu X, Wang Z and Li Q: Potential effect of smoking on semen quality through DNA damage and the downregulation of Chk1 in sperm. Mol Med Rep 14: 753-761, 2016.

16. Livak KJ and Schmittgen TD: Analysis of relative gene expression data using real-time quantitative PCR and the 2(-Delta Delta C(T)) Method. Methods 25: 402-408, 2001.

17. Krulewitch CJ: Reproductive Health of Active Duty Women in Medically Austere Environments. Mil Med 181 (1 Suppl): S63-S69, 2016

18. Copp T, McCaffery K, Azizi L, Doust J, Mol BWJ and Jansen J: Influence of the disease label 'polycystic ovary syndrome' on intention to have an ultrasound and psychosocial outcomes: A randomised online study in young women. Hum Reprod 32: 876-884, 2017.

19. Zheng J, Yin Q, Cao J and Zhang B: Obesity contributes more to increasing ApoB/ApoA1 ratio than hyperandrogenism in PCOS women aged 20-38 years in China. Exp Ther Med 13: 1337-1342, 2017.
20. Zhang W, Wu X, Ding M, Yu X, Liu G and Shi Y: Case-control based study between polymorphisms in the adiponectin gene and polycystic ovary syndrome. Zhonghua Fu Chan Ke Za Zhi 50: 825-829, 2015 (In Chinese).

21. Adeniji AA, Essah PA, Nestler JE and Cheang KI: Metabolic effects of a commonly used combined hormonal oral contraceptive in Women with and without polycystic ovary syndrome. J Womens Health (Larchmt) 25: 638-645, 2016.

22. Xi W, Yang Y, Mao H, Zhao X, Liu M and Fu S: Circulating anti-mullerian hormone as predictor of ovarian response to clomiphene citrate in women with polycystic ovary syndrome. J Ovarian Res 9: 3, 2016.

23. Timur H, Yimaz N, Kahyaoglu I, Inal HA and Erkaya S: The effect of serum and follicular fluid amyloid-associated protein levels on in vitro fertilization outcome in patients with polycystic ovary syndrome. J Assist Reprod Genet 32: 1637-1642, 2015.

24. Shi L, Liu S, Zhao W and Shi J: miR-483-5p and miR-486-5p are down-regulated in cumulus cells of metaphase II oocytes from women with polycystic ovary syndrome. Reprod Biomed Online 31: 565-572, 2015 .

25. Yang BZ, Cui W and Li J: Effects of electroacupuncture intervention on changes of quality of ovum and pregnancy out- come in patients with polycystic ovarian syndrome. Zhen Ci Yan Jiu 40: 151-156, 2015 (In Chinese).

26. Coskun S, Otu HH, Awartani KA, Al-Alwan LA, Al-Hassan S, Al-Mayman H, Kaya N and Inan MS: Gene expression profiling of granulosa cells from PCOS patients following varying doses of human chorionic gonadotropin. J Assist Reprod Genet 30: 341-352, 2013.

27. Palin MF, Bordignon VV and Murphy BD: Adiponectin and the control of female reproductive functions. Vitam Horm 90: 239-287, 2012.

28. Persani L, Rossetti R, Di Pasquale E, Cacciatore C and Fabre S: The fundamental role of bone morphogenetic protein 15 in ovarian function and its involvement in female fertility disorders. Hum Reprod Update 20: 869-883, 2014.

29. Zhai B, Liu H, Li X, Dai L, Gao Y, Li C, Zhang L, Ding Y, Yu X and Zhang J: BMP15 prevents cumulus cell apoptosis through CCL2 and FBN1 in porcine ovaries. Cell Physiol Biochem 32: 264-278, 2013.

30. Hussein TS, Froiland DA, Amato F, Thompson JG and Gilchrist RB: Oocytes prevent cumulus cell apoptosis by maintaining a morphogenic paracrine gradient of bone morphogenetic proteins. J Cell Sci 118: 5257-5268, 2005.

31. Wu XQ, Wang YQ, Xu SM, Liu JF, Bi XY, Wang ZQ and Zhang JP: The WNT/ $\beta$-catenin signaling pathway may be involved in granulosa cell apoptosis from patients with PCOS in North China. J Gynecol Obstet Biol Reprod (Paris): Oct 16, 2015 (Epub ahead of print). 